\title{
Dentoalveolar comparative study between removable and fixed cribs, associated to chincup, in anterior open bite treatment
}

\author{
Fernando César TORRES', Renato Rodrigues de ALMEIDA², Renata Rodrigues de ALMEIDA-PEDRIN³, Fernando \\ PEDRIN $^{4}$, Luiz Renato PARANHOS ${ }^{5}$

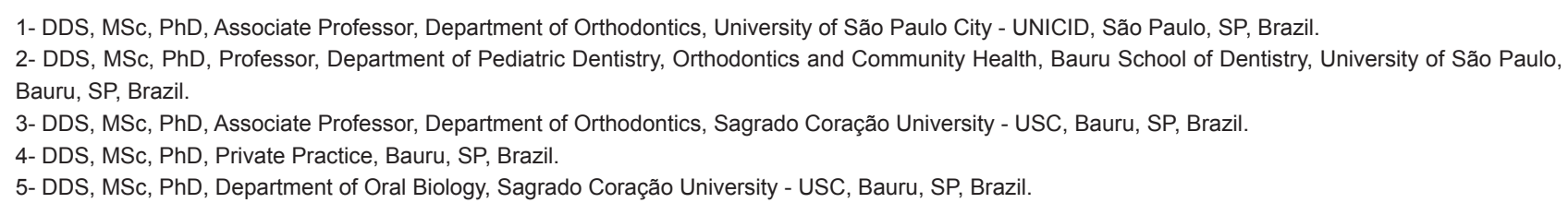

Corresponding address: Fernando C. Torres - UNICID - Universidade Cidade de São Paulo - R. Cesário Galeno, $432 / 448$ - Tatuapé - $03071-000$ - São Paulo - SP - Brasil - Phone: (005511) 21781200 - Fax: (005511) 69414848 - e-mail: fernandoctorres@yahoo.com

Received: November 16, 2010 - Modification: July 14, 2011 - Accepted: August 02, 2011

\section{ABSTRACT}

\begin{abstract}
bjective: The aim of this prospective study was to compare the dentoalveolar effects produced by two types of palatal crib, removable $(\mathrm{Rpc}+\mathrm{C})$ and fixed $(\mathrm{Fpc}+\mathrm{C})$, combined with chincup in growing patients with anterior open bite. Material and Methods: Each group comprised 30 patients, in the mixed dentition phase, with similar cephalometric characteristics and skeletal ages. Group $1(\mathrm{Rpc}+\mathrm{C})$ presented initial mean age of 8.3 years and mean anterior open bite of $4.0 \mathrm{~mm}$. Group $2(\mathrm{Fpc}+\mathrm{C})$ presented initial mean age of 8.54 years and mean anterior open bite of $4.3 \mathrm{~mm}$. The evaluation period comprised 12 months between initial (T1) and second lateral radiograph (T2). The T2-T1 changes were compared cephalometrically in the 2 groups using the non-paired t-test. Results: Vertical changes in the posterior dentoalveolar region were similar between the groups (about $1 \mathrm{~mm}$ ) and no significant differences were found in molar mesialization. The $\mathrm{Fpc}+\mathrm{C}$ group had in average $1.6 \mathrm{~mm}$ more improvement of the overbite as a result of greater maxillary incisor extrusion $(1.3 \mathrm{~mm})$. Patients in this group also presented less lingual tipping of maxillary incisors and more mandibular incisors uprighting. Conclusions: The $\mathrm{Fpc}+\mathrm{C}$ combination was more efficient in the correction of the negative overbite mainly due to greater extrusion of the maxillary incisors. However, the $\mathrm{Rpc}+\mathrm{C}$ appliance promoted better upper and lower incisor inclination, resulting in a more adequate overjet.
\end{abstract}

Key words: Open bite. Malocclusion. Orthodontics. Mixed dentition.

\section{INTRODUCTION}

Open bite is defined as a deficiency in the normal vertical overlap between antagonist teeth during occlusion $^{3,25}$, and it is more frequently present in the among incisors, being its prevalence about $17 \%$ in the mixed dentition ${ }^{19}$. Besides the high prevalence, anterior open bite is a major cause of masticatory and phonatory function impairment. This malocclusion also causes considerable aesthetic issues and may impact in the self-esteem of the affected patient.

According to the structures affected, anterior open bite can be divided into three main categories: dental, dentoalveolar and skeletal ${ }^{2}$. Dental and dentoalveolar open bite develop as a result of prolonged mechanical blockage of the normal vertical development of anterior teeth and alveolar process. The skeletal form, in turn, is characterized by a significant vertical skeletal discrepancy, with features such as counter-clockwise rotation of the palatine process, increased lower anterior facial height and gonial angle, short mandibular ramus and increased posterior dentoalveolar height in both mandible and maxilla ${ }^{18}$.

There are several etiological factors associated 
with anterior open bite. Environmental causes such as finger sucking habits, pacifiers, mouth breathing and tongue or lip thrusting, as well as tooth ankylosis and eruption disturbances seem to be predominant in the dental and dentoalveolar form. In fact, previous studies found anterior open bite in $78.5 \%$ of children with prolonged sucking habits ${ }^{19}$, and tongue thrusting was present in $100 \%$ of open bite cases ${ }^{23}$.

Although tongue thrust has been classified as primary, when it is the main cause of the malocclusion, and secondary, when the inadequate tongue position is just a result of a preexisting morphological alteration, this habit is most commonly cited in the literature as a consequence, not as a cause of the open bite ${ }^{20}$.

The development and severity of a malocclusion as anterior open bite, is not only determined by environmental factors, but also by the individual's growth pattern which is genetically determined. Inheritance is an extremely important etiologic factor of open bite; the more vertical is the facial growth pattern, the greater the probability of developing a skeletal anterior open bite ${ }^{12}$.

The skeletal facial pattern of patients with anterior open bite is in general more convex and the anterior facial height is increased ${ }^{9}$. There are protrusion and marked labial inclination of maxillary and mandibular incisors. Moreover, the profile convexity is aggravated by chin retrusion and remarkable lip protrusion ${ }^{5}$.

There is consensus that open bite should be treated early to take advantage of the active growth and to produce faster and more stable results; however, the differential diagnosis between dental and skeletal open bite and the treatment options for its correction are still controversial. It is essential for the clinician to distinguish a dentoalveolar from a skeletal open bite in order to eliminate the cause ${ }^{7}$. Unfortunately, in most cases this distinction is not so clear because both dental and skeletal characteristics are present.

Several studies have emphasized the importance

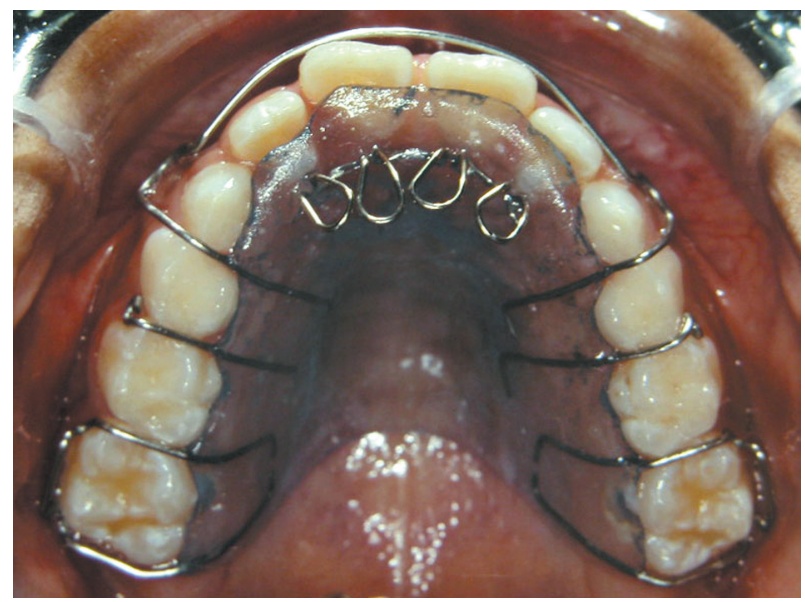

Figure 1- Removable palatal crib of the vertical control of the facial growth during the orthodontic treatment of anterior open bite, as it is highly associated with an hyperdivergent facial pattern ${ }^{5}$. Relative and true intrusion of posterior teeth has been proposed as an alternative to correct the anterior open bite. The use of high-pull headgear, bite-blocks, magnets ${ }^{24}$, transpalatal arch and chewing exercises ${ }^{7,23}$, tooth extraction and mesial movement of posterior teeth, and vertical ${ }^{8,13,21}$ or conventional chincup ${ }^{1,15-17,22}$ has been advocated with this purpose.

The treatment goals should include removing the local etiological factors in order to promote a normal anterior segment development. Palatal cribs have been reported as an excellent method of treatment, because it works as a mechanical barrier, preventing tongue thrusting and resting interposition as well as discouraging sucking habits. Furthermore, the appliance construction is simple, it can be easily customized, it is a lower cost appliance, and depending on the patient's compliance it can be fixed or removable. Even though several studies have demonstrated its effectiveness in the correction of anterior open bite, few have compared the effects produced by the fixed and removable palatal cribs $^{6}$.

The objective of this study was to compare the therapeutic effects in the dentoalveolar process of the fixed and removable palatal crib, both combined with chincup, in growing patients with anterior open bite.

\section{MATERIAL AND METHODS}

The sample of this prospective study was composed of 60 children selected according the following inclusion criteria: Brazilian Caucasian children, age ranging from 7-10 years, intertransitional mixed dentition period, open bite greater than $1 \mathrm{~mm}$, incisors and first permanent molars fully erupted, and Class I relationship. It were excluded patients previously orthodontically treated, with severe crowding (more than $4 \mathrm{~mm}$ ), with teeth absences and patients with TMJ trauma or disorder. This

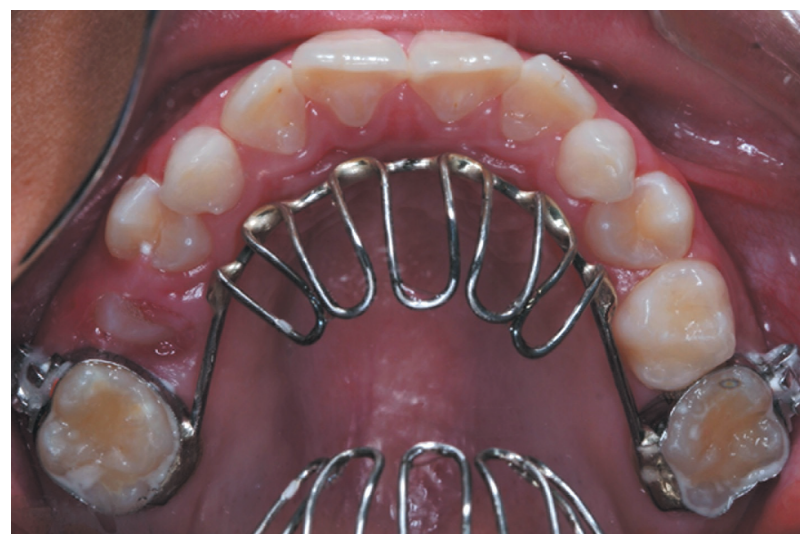

Figure 2- Fixed palatal crib 


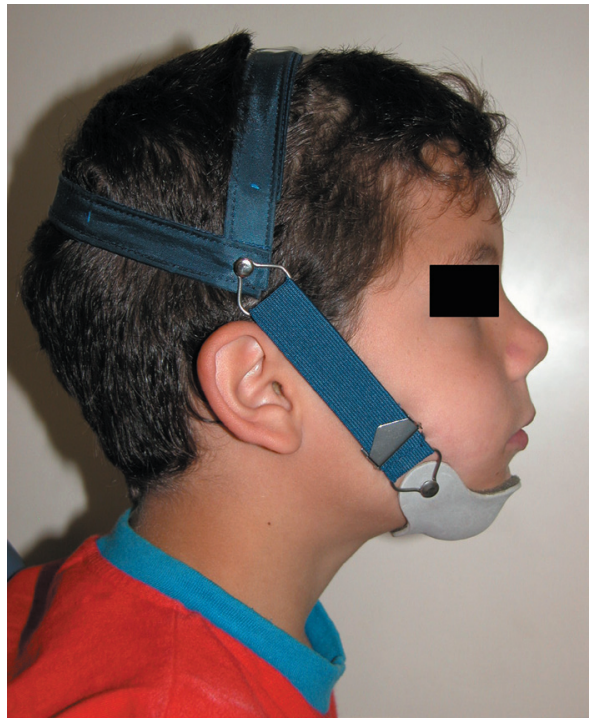

Figure 3- Chincup with the force vector directed to the condyle

Figure 4- Dentoalveolar variables used and their definitions study was approved by the University of São Paulo, Bauru School of Dentistry Institutional Review Board (Protocol number 14/2007). All subjects and their parents read and provided written informed consent after demonstrating full understanding of the purpose of this study.

The sample was divided in two groups according to the appliance used; Group 1 was composed by 30 patients that participated in a previous study 22 and who were treated with removable crib and chincup $(\mathrm{Rpc}+\mathrm{C})$. Group 2 comprised a new cohort of 30 children with anterior open bite consecutively selected and allocated to receive treatment with fixed palatal crib combined with chincup $(\mathrm{Fpc}+\mathrm{C})$.

Group 1 was composed of 22 females and 8 males (mean age of 8.33 years at T1). Patients in this group were instructed to wear a removable palatal crib (Figure 1) full-time except during meals and oral hygiene. Group 2, in turn, was composed of 19 females and 11 males (mean age of 8.54 years at T1) who used a fixed palatal crib (Figure 2). Additionally,

\begin{tabular}{|c|c|c|}
\hline Number & Abreviation & Description \\
\hline 1 & U6 Eruption & $\begin{array}{l}\text { First maxillary molar eruption: Distance from palatal plane (PP) to the line form by the most } \\
\text { mesial and most distal points of the maxillary first molar }\end{array}$ \\
\hline 2 & L6 Eruption & $\begin{array}{l}\text { First mandibular molar eruption: Distance from the mandibular plane (Go-Me) to the line } \\
\text { form between the most mesial and most distal points of the mandibular first molar }\end{array}$ \\
\hline 3 & Molars erupt diff & Molars eruption difference: Difference between L6 and U6 eruption (L6erup - U6erup) \\
\hline 4 & Overbite & $\begin{array}{l}\text { Vertical overlap: distance from the maxillary central incisor (U1) incisal edge to the } \\
\text { mandibular central incisor (L1) incisal edge }\end{array}$ \\
\hline 5 & L6-GoMe & $\begin{array}{l}\text { Mandibular first molar eruption assesed in its cuspid: Perpendicular distance between } \\
\text { mandibular plane and the mesio-buccal cuspid tip of L6 }\end{array}$ \\
\hline 6 & L1-GoMe & $\begin{array}{l}\text { Mandibular incisor extrusion: Perpendicular distance between mandibular plane and L1 } \\
\text { incisal edge }\end{array}$ \\
\hline 7 & U6-PP & $\begin{array}{l}\text { Maxillary first molar eruption assessed in its cuspid: Perpendicular distance between } \\
\text { palatal plane to the mesio-bucal cuspid tip of U6 }\end{array}$ \\
\hline 8 & U1-PP & $\begin{array}{c}\text { Maxillary incisor extrusion: Perpendicular distance between palatal plane and U1 incisal } \\
\text { edge }\end{array}$ \\
\hline 9 & U1.NA & Maxillary incisor inclination: Angle between U1 long axis and NA line \\
\hline 10 & U1-NA & Maxillary incisor protrusion/retrusion: Distance between U1 incisal edge and NA line \\
\hline 11 & L1.NB & Mandibular incisor inclination: Angle between L1 and NB line \\
\hline 12 & L1-NB & Mandibular incisor protrusion/retrusion: Distance between L1 incisal edge and NB line \\
\hline 13 & U6-FHp & $\begin{array}{l}\text { Anteroposterior displacement of the first maxillary molar: Horizontal distance between } \\
\text { mesio-buccal cuspid tip of U6 and S-FHp line (Sella line parallel to the modified Frankfort } \\
\text { horizontal plane) }\end{array}$ \\
\hline 14 & L6-FHp & $\begin{array}{l}\text { Anteroposterior displacement of the first mandibular molar: Horizontal distance between } \\
\text { the mesio-buccal cuspid tip of L6 and S-FHp line }\end{array}$ \\
\hline 15 & U1 Expo & $\begin{array}{l}\text { Maxillary incisor exposure: Vertical distance between the upper lip stomion point and U1 } \\
\text { incisal edge }\end{array}$ \\
\hline 16 & U1.L1 & Interincisor angle: Angle between U1 long axis and L1 long axis \\
\hline 17 & Overjet & Horizontal overlap: Distance between U1 incisal edge and L1 incisal edge \\
\hline 18 & FMA & Frankfurt x Mandibular Plane Angle: Angle between Frankfurt plane and mandibular plane. \\
\hline 19 & SN.GoGn & Angle between SN line and GoGn plane \\
\hline 20 & $\mathrm{ALFH}$ & Anterior lower facial height: Distance from anterior nasal spine to mentonian point (Me) \\
\hline 21 & PFH & height: Distance from point S to Go \\
\hline
\end{tabular}


all patients in both groups worn a high-pull chincup, delivering a force of $450-500 \mathrm{~g}$ per side ${ }^{14}$, with the force vector passing $45^{\circ}$ above the occlusal plane (Figure 3). Instructions were given to patients to use the chincup for 14-16 h/day.

The dentoalveolar changes produced after 1 year of continuous use of the two types of palatal crib were assessed and compared using the initial (T1), taken right before treatment, and the 1-year follow-up (T2) lateral cephalograms. Patients who may not have their malocclusions corrected during this period due to complicating factors such as severe open bite, vertical growth pattern or even lack of cooperation, remained in treatment until a positive vertical overlap of at least $1 \mathrm{~mm}$ was obtained. The 21 variables used to evaluate the dentoalveolar changes are defined and illustrated in Figure 4 and Figure 5 respectively.

One examiner (F.C.T.) hand-traced and then digitalized and analyzed all the 120 cephalograms using the Dentofacial Planner 7.0 software (Dentofacial Planner 7.0 Software Inc., Toronto,

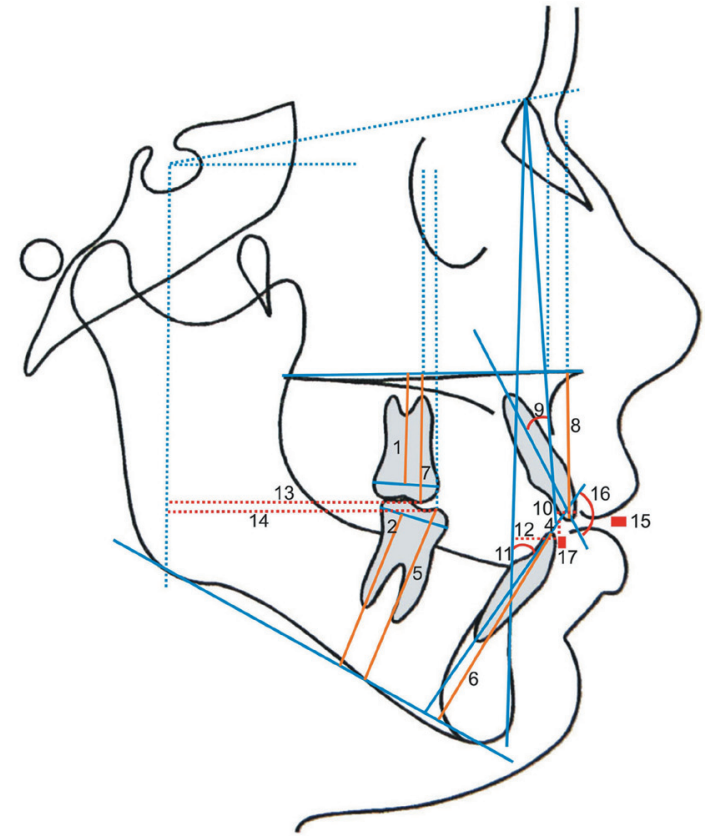

Figure 5-Angular and linear dentoalveolar measurements

Table 1- Mean initial and final age and period of treatment

\begin{tabular}{ccccc}
\hline GROUP & $\begin{array}{c}\text { INITIAL AGE } \\
\text { (Years) }\end{array}$ & $\begin{array}{c}\text { FINAL AGE } \\
\text { (Years) }\end{array}$ & $\begin{array}{c}\text { Treatment Period } \\
\text { (Years) }\end{array}$ & * $^{*}$ \\
\hline Group 1 & 8.33 & 9.33 & & \\
Rpc+C $(n=30)$ & $($ SD 0.73) & $($ SD 0.74) & 1.00 & $0.287($ NS) \\
Group 2 & 8.54 & 9.62 & 1.08 & \\
Fpc+C $(n=30)$ & (SD 0.88) & (SD 0.90) & & \\
\hline
\end{tabular}

${ }^{*} \mathrm{p}<0.05$ - NS: not significant

Table 2- Comparison of the initial dentoalveolar and skeletal characteristics

\begin{tabular}{|c|c|c|c|c|c|c|}
\hline \multirow[t]{2}{*}{$\begin{array}{c}\text { Dentoalveolar } \\
\text { Variables }\end{array}$} & \multicolumn{2}{|c|}{$\begin{array}{l}R p c+C \\
(n=30)\end{array}$} & \multicolumn{2}{|c|}{$\begin{array}{c}F p c+C \\
(n=30)\end{array}$} & \multirow[t]{2}{*}{$\mathbf{p}$} & \multirow[t]{2}{*}{ Sig } \\
\hline & Initial & SD & Final & SD & & \\
\hline U6 Eruption & 15.05 & 1.69 & 13.75 & 2.06 & 0.009 & Sig \\
\hline L6 Eruption & 25.19 & 2.48 & 25.28 & 1.91 & 0.866 & NS \\
\hline Molars erupt diff & 10.13 & 2.75 & 11.52 & 2.10 & 0.031 & Sig \\
\hline Overbite & -4.07 & 2.37 & -4.33 & 1.97 & 0.641 & NS \\
\hline L6-GoMe & 28.43 & 2.58 & 28.65 & 1.79 & 0.694 & NS \\
\hline L1-GoMe & 37.00 & 2.83 & 35.65 & 2.50 & 0.056 & NS \\
\hline U6-PP & 18.65 & 1.66 & 17.70 & 2.18 & 0.063 & NS \\
\hline U1-PP & 24.97 & 3.38 & 23.00 & 3.28 & 0.025 & Sig \\
\hline U1.NA & 26.87 & 6.01 & 27.45 & 5.84 & 0.704 & NS \\
\hline U1-NA & 4.06 & 2.38 & 3.29 & 2.32 & 0.207 & NS \\
\hline L1.NB & 34.18 & 6.28 & 28.93 & 6.85 & 0.003 & Sig \\
\hline L1-NB & 6.81 & 2.81 & 4.95 & 2.05 & 0.004 & Sig \\
\hline U6-FHp & 36.37 & 4.50 & 39.68 & 4.03 & 0.003 & Sig \\
\hline L6-FHp & 37.88 & 4.44 & 39.98 & 4.22 & 0.065 & NS \\
\hline U1 Expo & 0.34 & 1.94 & 0.09 & 2.32 & 0.657 & NS \\
\hline U1.L1 & 112.70 & 8.31 & 117.95 & 10.59 & 0.036 & Sig \\
\hline Overjet & 5.45 & 2.16 & 5.31 & 2.39 & 0.826 & NS \\
\hline
\end{tabular}

$p<0.05$ - Sig: Significant - NS: Not significant 
Table 3- Comparison of dentoalveolar changes at 1 year follow-up (T2-T1)

\begin{tabular}{|c|c|c|c|c|c|c|}
\hline \multirow[t]{2}{*}{$\begin{array}{c}\text { Dentoalveolar } \\
\text { Variables }\end{array}$} & \multicolumn{2}{|c|}{$\begin{array}{c}\mathrm{Rpc}+\mathrm{C} \\
(\mathrm{n}=30)\end{array}$} & \multicolumn{2}{|c|}{$\begin{array}{c}F p c+C \\
(n=30)\end{array}$} & \multirow[t]{2}{*}{$\mathbf{p}$} & \multirow[t]{2}{*}{ Sig } \\
\hline & $\mathbf{x}$ & DP & $\mathbf{x}$ & DP & & \\
\hline U6 Eruption & 0.92 & 1.52 & 1.20 & 1.86 & 0.516 & NS \\
\hline L6 Eruption & 1.00 & 1.26 & 0.65 & 1.67 & 0.359 & NS \\
\hline Molars erupt diff & 0.09 & 1.99 & -0.56 & 2.86 & 0.312 & NS \\
\hline Overbite & 3.86 & 1.85 & 5.44 & 1.97 & 0.002 & Sig \\
\hline L6-GoMe & 1.06 & 1.31 & 0.75 & 1.60 & 0.430 & NS \\
\hline L1-GoMe & 2.43 & 1.11 & 2.27 & 1.69 & 0.666 & NS \\
\hline U6-PP & 0.88 & 1.55 & 0.92 & 1.73 & 0.925 & NS \\
\hline U1-PP & 2.33 & 1.39 & 3.62 & 2.25 & 0.009 & Sig \\
\hline U1.NA & -6.13 & 5.96 & -3.01 & 5.69 & 0.042 & Sig \\
\hline U1-NA & -0.69 & 2.89 & 0.41 & 2.08 & 0.094 & NS \\
\hline L1.NB & -3.18 & 3.98 & -5.44 & 5.71 & 0.080 & NS \\
\hline L1-NB & -0.40 & 1.27 & -0.78 & 1.56 & 0.301 & NS \\
\hline U6-FHp & 0.93 & 1.58 & 0.61 & 3.24 & 0.638 & NS \\
\hline L6-FHp & 1.40 & 2.71 & 0.33 & 3.07 & 0.167 & NS \\
\hline U1 Expo & 2.46 & 1.60 & 2.29 & 2.15 & 0.724 & NS \\
\hline U1.L1 & 9.66 & 6.88 & 9.58 & 9.21 & 0.969 & NS \\
\hline Overjet & -0.75 & 2.03 & 0.40 & 1.93 & 0.025 & Sig \\
\hline
\end{tabular}

$p<0.05-X=M e a n$ change - Sig: Significant - NS: Not significant

Canada). Intra-examiner reliability was assessed retracing and remeasuring 40 cephalograms (33\%) 1 month later. The random error was estimated using Dahlberg's formula. The systematic error was calculated by a paired $t$-test, comparing $33 \%$ of measurements, after a minimum period of 30 days. Initial dentoalveolar characteristics, initial age, final age, and follow-up period as well as 1 year posttreatment changes were compared using not paired $t$-test $(\mathrm{p}<0.05)$.

\section{RESULTS}

No systematic or random errors were found. As shown in Table 1, initial and final ages and observation period in $\mathrm{Rpc}+\mathrm{C}$ and $\mathrm{Fpc}+\mathrm{C}$ groups were similar. Seven dentoalveolar characteristics presented significant differences between groups at T1 and no skeletal variables presented significant differences (Table 2). Regarding the comparison of dentoalveolar changes after 1 year of treatment, significant differences were found in 4 variables. While the $\mathrm{Rpc}+\mathrm{C}$ group had greater improvement in overjet and maxillary incisor inclination, in the $\mathrm{Fpc}+\mathrm{C}$ group there was a greater amount of maxillary incisor extrusion resulting in greater correction of the negative overbite (Table 3 ).

\section{DISCUSSION}

\section{Characteristics of sample}

The correction of anterior open bite, as previously reported ${ }^{11}$, is indicated during the period of mixed dentition, period that involves the patient's initial age in our study. Since this study involved patients in active growth period, it was essential to have groups with similar ages to allow the comparison of the effects produced by the two types of palatal crib (mean of 8.33 years for Group 1 and 8.54 years for Group 2).

Overall, groups 1 and 2 presented a similar open bite pattern. Most of the initial dentoalveolar characteristics were similar among groups especially the severity of the open bite, overjet, and maxillary incisor exposure, inclination and protrusion, among others. The skeletal measurements evaluated also showed pre-treatment similarity. However, there were also some dentoalveolar variables that were different. Anterior (U1-PP) and posterior dentoalveolar height (U6 eruption), for instance, were greater in group 1 - almost $2 \mathrm{~mm}$ and 1.3 $\mathrm{mm}$, respectively. Inter-incisor angle was also $5.3^{\circ}$ closer in group 1 due to the greater mandibular incisor inclination and protrusion( $L 1 . N B=34.18^{\circ}$, $\mathrm{L} 1-\mathrm{NB}=6.81 \mathrm{~mm}$ ) when compared to Group 2 ( $\mathrm{L} 1$. $\mathrm{NB}=28.93^{\circ}, \mathrm{L} 1-\mathrm{NB}=4.95 \mathrm{~mm}$ ). These differences in the initial characteristics would be expected because individual variances. Even though, our sample was selected following strictly the inclusion criteria and patients represented a specific Brazilian population (Caucasians), it was difficult to obtain a completely homogeneous cohort.

\section{Methodology}

In many cases it is not clear whether both dentoalveolar and skeletal components are involved 
in the anterior open bite. The vertical control is important in order to avoid increasing the facial height and control the facial vertical growth if possible. For this reason, we used the chincup, as advocated by many authors $4,8,13,16,17$, combined with the removable and fixed palatal cribs, whose primary function is to prevent the aberrant tongue function and inhibit sucking habits allowing for normal development of the anterior segment. It was necessary to standardize the time of the chincup use in all patients to avoid interferences in the comparison of the intraoral appliances' effect.

We found in our previous studies ${ }^{15,22}$ that the use of the chincup did not provide a significant vertical growth control but the use of a removable palatal crib produced an effective correction of the negative vertical overlap and improved the maxillary and mandibular incisors inclination. Thus, we speculated that the use of a fixed palatal crib would correct the dentoalveolar alteration more efficiently than the removable appliance because it eliminates the need for patient cooperation, increasing the efficacy of the treatment because the full-time use.

\section{Comparison of changes at 1 year follow-up (T2-T1) \\ Posterior dentoalveolar region}

The posterior dentoalveolar height in maxilla and mandible increased similarly, about $1 \mathrm{~mm}$, in both the $\mathrm{Rpc}+\mathrm{C}$ and $\mathrm{Fpc}+\mathrm{C}$ groups. Since the age and initial cephalometric characteristics were similar among groups and all patients used the same type of chincup, no differences in the vertical development of this region were expected. To verify the impact of the chincup use from the normal growth in the development of the vertical dentoalveolar height $t^{4,13,17}$ it would be necessary to compare our two experimental groups to a third control group. However, in a previous study ${ }^{22}$ we compared the patients treated with $\mathrm{Rpc}+\mathrm{C}$ (group 1 ) with a control group and the results shown that real or relative molar intrusion was not obtained by the use of the chincup.

We also measured the anteroposterior displacement of the first maxillary molars to verify whether the fixed crib would promote a greater anterior displacement of these teeth than the removable type. Theoretically, the constant pressure of the tongue against a fixed palatal crib could mesialize maxillary molars leading to the development of a Class II malocclusion ${ }^{10}$. This did not occur; in fact, there were not significant differences in the anteroposterior displacement of maxillary or mandibular molars between the $\mathrm{Rpc}+\mathrm{C}$ and $\mathrm{Fpc}+\mathrm{C}$ groups. Furthermore, previous studies has already shown that the use of removable palatal crib do not cause greater maxillary molar mesialization than which occurs in patients without treatment ${ }^{16,22}$.
Therefore, the use of spurs - to maintain the tongue away from the appliance avoiding anterior pressure of the maxillary molars - instead of the palatal crib is not justified.

\section{Anterior dentoalveolar region}

It has been well documented that the correction of the anterior open bite when a palatal crib is used, occurs mainly due to dentoalveolar changes, such as extrusion and verticalization of maxillary and mandibular incisors ${ }^{1-2}$. On average, we found that the percentage of anterior open bite correction was higher in patients who used $\mathrm{Fpc}+\mathrm{C}$ than in the $\mathrm{Rpc}+\mathrm{C}$ group. Changes were significantly different in the maxillary incisor extrusion (U1-PP) and overbite; the $\mathrm{Fpc}+\mathrm{C}$ group showed on average $1.3 \mathrm{~mm}$ greater maxillary incisor extrusion and $1.6 \mathrm{~mm}$ more improvement in the overbite than the $\mathrm{Rpc}+\mathrm{C}$ group; that means, the fixed palatal crib was $50 \%$ more effective in promoting maxillary incisor extrusion and overbite improvement.

At the end of 12 months of treatment, of a total of 30 patients per group, positive vertical overlap was achieved in 15 patients in the $\mathrm{Rpc}+\mathrm{C}$ group and in 21 children in the $\mathrm{Fpc}+\mathrm{C}$ group. The less patient's compliance requirement in the $\mathrm{Fpc}+\mathrm{C}$ group was probably the main reason of the greater effectiveness of this treatment ${ }^{12}$.

In open bite cases, in addition to infraocclusion, incisors are usually buccally tipped. The increased incisor angulation may be a consequence of an abnormal tongue posture, digital and pacifier sucking, adenoid hypertrophy, or mouth breathing, among others. It is very important to normalize the incisor inclination as part of the treatment. It has been shown, that both removable and fixed palatal cribs work effectively correcting buccally tipped incisors ${ }^{6}$.

In the present study, after 1 year of treatment, the $\mathrm{Rpc}+\mathrm{C}$ group achieved almost two times greater palatal tipping of the maxillary incisors (U1. $\mathrm{NA}=-6.1^{\circ}$ ) than the $\mathrm{Fpc}+\mathrm{C}$ group (U1.NA=3.01\%). Although not significant, $0.7 \mathrm{~mm}$ of retrusion of these teeth was also observed in the $\mathrm{Rpc}+\mathrm{C}$ group, while incisor protrusion occurred $(0.4 \mathrm{~mm})$ in the $\mathrm{Fpc}+\mathrm{C}$ group. As suggested by previous studies, this difference may be the result of the activation of the vestibular arch and adjustment of the palatal acrylic coverage that was regularly performed in the removable crib in order to enhance the effect of this appliance. Nevertheless, even with less maxillary incisor palatal tipping, there was greater overbite improvement in the $\mathrm{Fpc}+\mathrm{C}$ group due to greater maxillary incisor extrusion.

Interestingly, although not statistically significant, at $\mathrm{T} 2$ the $\mathrm{Fpc}+\mathrm{C}$ group showed greater lingual tipping of the mandibular incisors $\left(2.3^{\circ}\right.$ greater than the $\mathrm{Rpc}+\mathrm{C}$ group). The greater lingual tipping in these teeth was also accompanied by a greater retrusion 
in the $\mathrm{Fpc}+\mathrm{C}$ group. As a result of the differences in the changes occurred in the maxillary and mandibular incisor inclination, the interincisal angle (U1.L1) increased similarly ( $9.6^{\circ}$ approximately) in both groups. However, the change in overjet was significantly different; while it decreased $0.8 \mathrm{~mm}$ in the $\mathrm{Rpc}+\mathrm{C}$ group, it increased $0.4 \mathrm{~mm}$ in the Fpc $+\mathrm{C}$ group.

The differences in maxillary and mandibular incisor inclination may be a result of the differences in the mode of action between the removable and fixed crib; the later does not have a labial arch and does not promote active maxillary incisor inclination, depending only in the normalization of the tongue and perioral muscle function to produce this effect. On the other hand, when a fixed crib is used the lingual pressure on the mandibular incisors produced by the perioral muscles, especially during swallowing, is not counterbalance by the tongue because it is permanently maintained in a backward position. This change in the muscle equilibrium may cause the changes in mandibular incisors inclination. The use of a mandibular lip-bumper would minimize the verticalization of mandibular incisors during the use of the fixed crib, improving its effectiveness in the correction of the overbite and avoiding the undesired increase of the overjet.

Despite the less amount of correction of the negative overbite, the removable palatal crib showed better effects on the positioning of the incisors and consequently in the overjet. It still depends on patient compliance for use, but, in many cases it provides greater comfort than the fixed palatal crib because patients can start using the appliance gradually, and it can be removed for meals and for oral hygiene, which would be favorable from the psychological point of view.

\section{CONCLUSIONS}

In summary, when compared the dentoalveolar effects of the $\mathrm{Rpc}+\mathrm{C}$ and the $\mathrm{Fpc}+\mathrm{C}$ appliances during the early treatment of the open bite, $\mathrm{Fpc}+\mathrm{C}$ appliance was more efficient in the correction of the negative overbite mainly due to greater extrusion of the maxillary incisors. However, the Rpc $+\mathrm{C}$ appliance showed better effects on the positioning of the incisors and consequently on the correction of overjet.

\section{REFERENCES}

1- Almeida RR, Henriques JFC, Almeida MR, Vasconcelos MHF. Early treatment of anterior open bite - prevention of orthognatic surgery. In: Davidovich Z, Mah J (ed.). Biological mechanisms of tooth eruption, resorption and replacement by implants. Boston: Harvard Society for the Advancement of Orthodontics; 1998. p. 585-8.

2- Almeida RR, Ursi WJ. Anterior open bite. Etiology and treatment. Oral Health. 1990;80(1):27-31.
3- Arat $\mathrm{M}$, Iseri $\mathrm{H}$. Orthodontic and orthopaedic approach in the treatment of skeletal open bite. Eur J Orthod. 1992;14(3):207-15. 4- Basciftci FA, Karaman AI. Effects of a modified acrylic bonded rapid maxillary expansion appliance and vertical chin cap on dentofacial structures. Angle Orthod. 2002;72(1):61-71.

5- English JD. Early treatment of skeletal open bite malocclusions. Am J Orthod Dentofacial Orthop. 2002;121(6):563-5.

6- Giuntini V, Franchi L, Baccetti T, Mucedero M, Cozza P. Dentoeskeletal changes associated with fixed and removable appliances with a crib in open-bite patients in the mixed dentition. Am J Orthod Dentofac Orthop. 2008;133:77-80.

7- Insoft MD, Hocevar RA, Gibbs $\mathrm{CH}$. The nonsurgical treatment of a Class II open bite malocclusion. Am J Orthod Dentofacial Orthop. 1996;110:598-605.

8- Isçan HN, Dinçer M, Gültan A, Meral O, Taner-Sarisoy L. Effects of vertical chincap therapy on the mandibular morphology in openbite patients. Am J Orthod Dentofacial Orthop. 2002;122:506-11. 9- Ishizaka GQ, Attizzani A, Takahashi T, Maruo H, Miyahara M, Rino W. Anterior open bite in Class I malocclusion individuals: a cephalometric comparative study. J Bras Ortodon Ortop Facial. 2001;6:412-20.

10- Justus R. Correction of anterior open bite with spurs: longterm stability. World J Orthod. 2001;2:219-31.

11- Mizrahi E. A review of anterior open bite. $\mathrm{Br}$ J Orthod. $1978 ; 5: 21-7$.

12- Nielsen IL. Vertical malocclusions: etiology, development and some aspects of treatment. Angle Orthod. 1991;61:247-60. 13- Pearson LE. Treatment of a severe open bite excessive vertical pattern with an ecletic non-surgical approach. Angle Orthod. 1991;61:71-6.

14- Pearson LE. Vertical control in treatment of patients having backward-rotational growth tendencies. Angle Orthod. 1978;48:132-40.

15- Pedrin F, Almeida MR, Almeida RR, Almeida-Pedrin RR, Torres FC. A prospective study of the treatment effects of a removable appliance with palatal crib combined with high-pull chincup therapy in anterior open-bite patients. Am J Orthod Dentofac Orthop. 2006;129:418-23.

16- Ritucci R, Nanda R. The effect of chin cup therapy on the growth and development of the cranial base and midface. Am J Orthod Dentofacial Orthop. 1986;90:475-83.

17- Sankey WL, Bushang PH, English J, Owen AH $3^{\text {rd }}$. Early treatment of vertical skeletal dysplasia: the hyperdivergent phenotype. Am J Orthod Dentofacial Orthop. 2000;118:317-27. 18- Schudy FF. Vertical growth versus anteroposterior growth as related to function and treatment. Angle Orthod. 1964;34:75-93. 19- Silva Filho OG, Gonçalves RMG, Maia FA. Sucking habits: clinical management in dentistry. J Clin Pediatr Dent. 1991;15:137-56. 20- Speidel TM, Isaacson RJ, Worms FW. Tongue thrust therapy and anterior dental open-bite. A review of new facial growth data. Am J Orthod. 1972;62:287-95.

21- Spyropoulos MN. An early approach for the interception of skeletal open bite: a preliminary report. J Pedod. 1985;9:200-9. 22- Torres FC, Almeida RR, Almeida MR, Almeida-Pedrin RR, Pedrin $\mathrm{F}$, Henriques JF. Anterior open bite treated with a palatal crib and high-pull chin cup therapy. A prospective randomized study. Eur J Orthod. 2006;28:610-7.

23- Warren JJ, Bishara SE. Duration of nutritive habits and nonnutritive sucking behaviors and their effects on the dental arches in the primary dentition. Am J Orthod Dentofacial Orthop. 2002;121:347-56.

24- Woods MG, Nanda RS. Intrusion of posterior teeth with magnets: an experiment in nongrowing baboons. Am J Orthod Dentofacial Orthop. 1991;100:393-400.

25- Worms FW, Meskin LH, Isaacson RJ. Open bite. Am J Orthod Dentofacial Orthop. 1971;59:589-95. 